\title{
Bioinformatics and functional analyses of key genes and pathways in human clear cell renal cell carcinoma
}

\author{
JINXING WANG ${ }^{1}$, LUSHUN YUAN $^{1}$, XINGNIAN LIU $^{1}$, GANG WANG $^{1}$, \\ YUAN ZHU $^{1,2}$, KAIYU QIAN $^{1,3,4}$, YU XIAO $^{1,2,4}$ and XINGHUAN WANG ${ }^{1}$ \\ ${ }^{1}$ Department of Urology; ${ }^{2}$ Laboratory of Precision Medicine, Zhongnan Hospital of Wuhan University; \\ ${ }^{3}$ Department of Urology, The Fifth Hospital of Wuhan; ${ }^{4}$ Department of Biological Repositories, \\ Zhongnan Hospital of Wuhan University, Wuhan, Hubei 430071, P.R. China
}

Received June 19, 2017; Accepted December 11, 2017

DOI: $10.3892 / \mathrm{ol} .2018 .8473$

\begin{abstract}
Clear cell renal cell carcinoma (ccRCC) is the most common type of kidney cancer. The present study was conducted to explore the mechanisms and identify the potential target genes for ccRCC using bioinformatics analysis. The microarray data of GSE15641 were screened on Gene-Cloud of Biotechnology Information (GCBI). A total of 32 ccRCC samples and 23 normal kidney samples were used to identify differentially expressed genes (DEGs) between them. Subsequently, the clustering analysis and functional enrichment analysis of these DEGs were performed, followed by protein-protein interaction (PPI) network, and pathway relation network. Additionally, the most significant module based on PPI network was selected, and the genes in the module were identified as hub genes. Furthermore, transcriptional level, translational level and survival analyses of hub genes were performed to verify the results. A total of 805 genes, 403 upregulated and 402 downregulated, were differentially expressed in ccRCC samples compared with normal controls. The subsequent bioinformatics analysis indicated that the small molecule metabolic process and the metabolic pathway were significantly enriched. A total of 7 genes, including membrane metallo-endopeptidase $(M M E)$, albumin $(A L B)$, cadherin 1 $(\mathrm{CDH})$, prominin 1 (ROMI), chemokine ( $\mathrm{C}-\mathrm{X}-\mathrm{C}$ motif) ligand 12 (CXCL12), protein tyrosine phosphatase receptor type $\mathrm{C}(P T P R C)$ and intercellular adhesion molecule 1 $(I C A M 1)$ were identified as hub genes. In brief, the present study indicated that these candidate genes and pathways may aid in deciphering the molecular mechanisms underlying the
\end{abstract}

Correspondence to: $\mathrm{Dr} \mathrm{Yu}$ Xiao or Dr Xinghuan Wang, Department of Urology, Zhongnan Hospital of Wuhan University, 169 Donghu Road, Wuhan, Hubei 430071, P.R. China

E-mail:yu.xiao@whu.edu.cn

E-mail: wangxinghuan@whu.edu.cn

Key words: bioinformatics analysis, clear cell renal cell carcinoma, differentially expressed genes, protein-protein interaction network, hub genes development of ccRCC, and may be used as therapeutic targets and diagnostic biomarkers of ccRCC.

\section{Introduction}

Kidney cancer is the ninth most frequent type of cancer in men and fourteenth in women worldwide; the incidence of kidney cancer is increasing throughout the world amongst all age groups and races (1). Kidney cancer was the cause of $\sim 143,000$ mortalities in 2012 worldwide, among which, clear cell renal cell carcinoma (ccRCC) accounted for $70 \%$ (2). Numerous studies have been performed to explore the pathogenesis of ccRCC, and many genes were identified as having an association with the tumorigenesis of ccRCC (3-5). For example, a previous study reported that Von Hippel-Lindau (VHL) loss induced gene expression changes that were independent on hypoxia inducible factor (HIF) and were responsible for the development of renal cancer (6). It was demonstrated that drugs targeting the pVHL-HIF-vascular endothelial growth factor (VEGF) pathway had been applied in the clinic and proven to have superiority over cytokine therapies (7). However, the VHL mutant alone was inadequate for ccRCC development (8).

In recent decades, high-throughput technology, including microarray analysis and RNA sequencing, have provided researchers with large expression data sets. Bioinformatics and computational techniques have been well applied in the studies of various tumors, and confirmed to be efficient and reliable in identifying novel tumor markers for cancer diagnosis and targeted treatments (9). In the present study, the microarray data (GSE15641), containing $32 \mathrm{ccRCC}$ samples and 23 normal kidney samples, was selected and analyzed by a series of bioinformatics analyses. Furthermore, the results were verified by OncoLnc, Gene Expression Profiling Interactive Analysis (GEPIA) and the Human Protein Atlas database data. The purpose of the present study was to identify potential target genes that may serve a role in ccRCC development.

\section{Materials and methods}

Microarray data. Gene-Cloud of Biotechnology Information (GCBI; Shanghai, China) is a powerful platform that provides services, including molecular medical information solutions, 
platform data services and cloud genetic analysis (www.gcbi. com.cn). It contains 120 million copies of genomic samples, $\sim 90,000$ tumor samples and as much as 17 million copies of genetic information. Additionally, the GCBI tool can be used to retrieve and analyze data from The National Center for Biotechnology Information $(10,11)$. The gene expression profiles of GSE15641, which were obtained based on the platform of GPL96, Affymetrix Human Genome U133A Array, were screened on GCBI to conduct the subsequent analysis. This dataset contained 92 samples, including 32 ccRCC tumors, 11 papillary RCC kidney tumors, 6 chromophobe RCC kidney tumors, 20 non-RCC renal tumors and 23 normal kidney samples. The 32 ccRCC samples and 23 normal kidney controls were selected to perform the analysis in the current study.

Identification of differentially expressed genes (DEGs). The GCBI online laboratory provides seven function modules, including sample grouping, differential expression analysis, gene ontology (GO) function analysis, Kyoto Encyclopedia of Genes and Genomes (KEGG) pathway enrichment analysis, and network analysis (pathway relation network, for example). Sample data were uploaded to GCBI online laboratory to conduct the subsequent analysis and DEGs with a fold change $\geq 2$ and a false discovery rate $(\mathrm{FDR})<0.05$ were selected. The hierarchical clustering were implemented using two methods: Unweighted pair-group method with arithmetic averages (12) and Pearson correlation.

Function and pathway enrichment analysis. The function and signaling pathway analysis of the selected DEGs were performed on the GCBI online laboratory using its GO function and KEGG pathway enrichment analysis modules. $\mathrm{P}<0.05$ was set in the aforementioned analyses and the results were visualized using two maps via the ggplot $2 \mathrm{R}$ package (https://CRAN.R-project.org/package=ggplot2) (13). $\mathrm{GO} /$ pathway analysis was performed using Fisher's exact test and represented in a $2 \times 2$ contingency table (Table I). To correct errors following multiple comparison analysis, the Benjamini-Hochberg step-up method was used to control the FDR.

Protein-protein interaction (PPI) network and pathway association network. Search Tool for the Retrieval of Interacting Genes (STRING, www.string-db.org/) is a database of known and predicted protein interactions, and provides a platform for users to evaluate the PPI information freely (14). To evaluate the interactive associations among DEGs, these were mapped to STRING, and only the interactions with a combined score $>0.4$ were selected. Subsequently, PPI networks were constructed using Cytoscape v3.4.0 software (cytoscape. org/) (15). The pathway association network was performed on GCBI using its network analysis module.

Hub gene selection and validation. The most significant module of PPI network was discriminated using the Molecular Complex Detection (MCODE) plug-in with the MCODE score $>3$ and number of nodes $>4$ (16). Genes in this module were considered as hub genes. Subsequently, transcriptional level analysis on the GEPIA database (gepia.cancer-pku.
Table I. $2 \times 2$ contingency table of Fisher's exact test in the $\mathrm{GO} /$ pathway analysis.

\begin{tabular}{lccc}
\hline Genes & DEGs & Non-DEGs & Total \\
\hline $\begin{array}{l}\text { Genes in the } \\
\text { GO/pathway }\end{array}$ & $n_{f}$ & $n_{f}-n_{f}$ & $n$ \\
$\begin{array}{l}\text { Genes out of the } \\
\text { GO/pathway }\end{array}$ & $N_{f}-n_{f}$ & $N-N_{f}-\left(n_{f}-n_{f}\right)$ & $N-n$ \\
Total & $N_{f}$ & $N-N_{f}$ & $N$ \\
\hline
\end{tabular}

$n_{f}$, the number of DEGs in the GO/pathway; $N_{f}$, the number of DEGs; $n$, the number of genes in the GO/pathway; $N$, the total number of genes in the annotation system. DEG, differentially expressed genes.

cn/index.html) (17), translational level analysis on the Human protein atlas database (www.proteinatlas.org/) (18) and survival analysis on the OncoLnc database (www.oncolnc.org/) (19) of hub genes were performed to verify the present results.

\section{Results}

Identification of DEGs. Under the threshold of FDR $<0.05$ and fold change $\geq 2$, a total of 805 genes were identified, including 403 up- and 402 downregulated genes. DEG expression heat map (top 50 up- and downregulated genes) and sample cluster analysis are presented in Fig. 1.

Functional and pathway enrichment analysis. The top $20 \mathrm{GO}$ and KEGG terms are listed in Fig. 2. As illustrated, the small molecule metabolic process and the metabolic pathway were significantly enriched. In addition, analysis of the association between the hub genes, and GO and KEGG terms was also performed. GO function analysis demonstrated small molecule metabolic processes, as well as pathways involved in viral myocarditis, staphylococcus infection, rheumatoid arthritis, protein digestion absorption, 'pathways in cancer' (KEGG map no. 05200, referring to signaling pathways associated with tumorigenesis) and cell adhesion molecules were also significantly enriched. Functional and pathway enrichment analysis models of GCBI were performed based on all DEGs.

PPI network and pathway relation network. Based on the STRING database, the PPI network was constructed using Cytoscape software (Fig. 3A). The most significant module with a MCODE score of 6.667 is illustrated in Fig. 3B. Pathway relation network (Fig. 3C) demonstrated that the mitogen-activated protein kinase (MAPK) signaling pathway and KEGG map no. 05200, 'pathways in cancer' were associated with RCC and that energy metabolism (centered on the citrate cycle) served a crucial role in RCC development.

Hub gene and validation. The most significant module with a MCODE score of 6.667 is illustrated in Fig. 3B. There were 5 downregulated hub genes, including membrane metallo-endopeptidase $(M M E)$, albumin $(A L B)$, cadherin $1(C D H 1)$, prominin 1 (ROMI), chemokine $(C-X-C$ motif) ligand 12 (CXCL12), and 2 upregulated hub genes including protein 
A
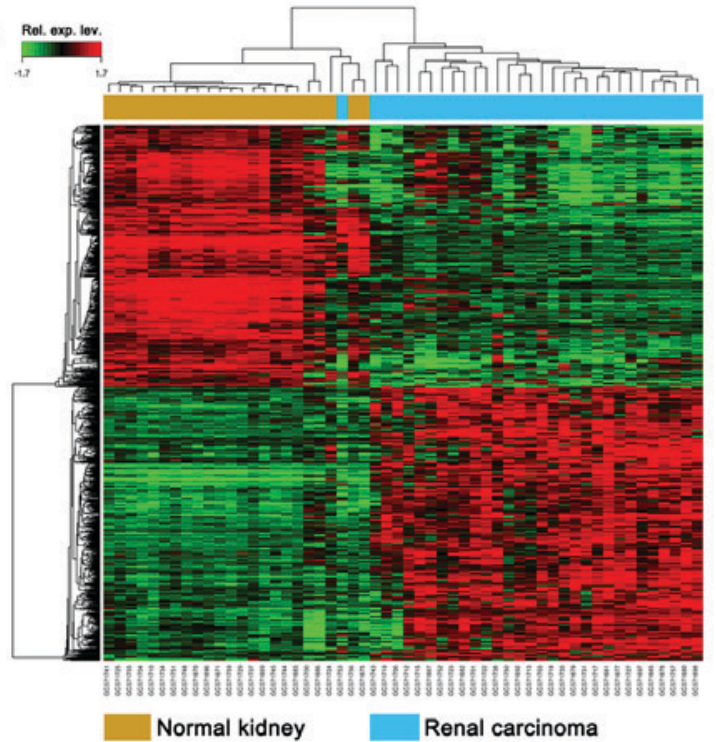

B

Cluster dendrogram

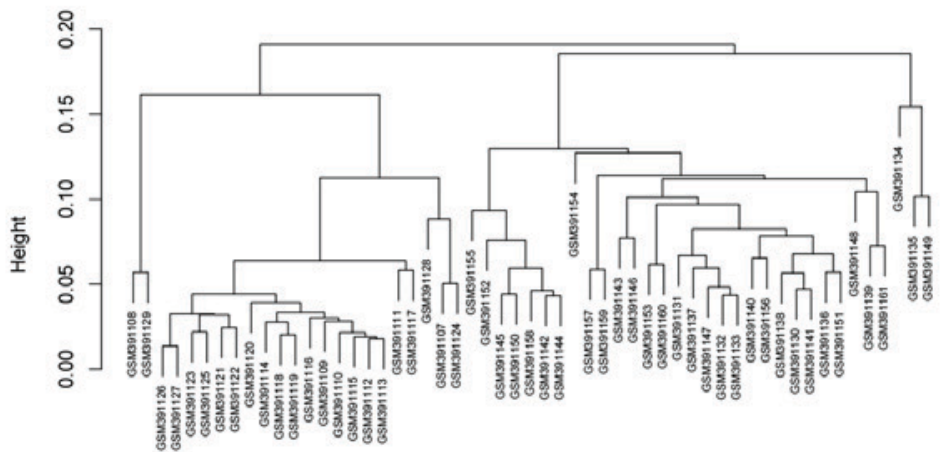

Figure 1. Samples clustering (GSE15641). (A) Heat map of the differentially expressed genes. Green represents downregulated genes and red represents upregulated genes. The cluster above the heat map represents the sample cluster, and the cluster on the left of the heat map represents the clustering of genes. The hierarchical clustering are implemented using the unweighted pair-group method with arithmetic averages method. The scale bar in the top left corner ranges from -1.7 to 1.7 indicates the relative expression level (rel. exp. lev.), calculated by the individual fold changes. (B) Cluster dendrogram for all samples in the GSE15641 using Pearson's correlation method. The height ranges from 0.00 to 0.20 represents relative coefficient.

A

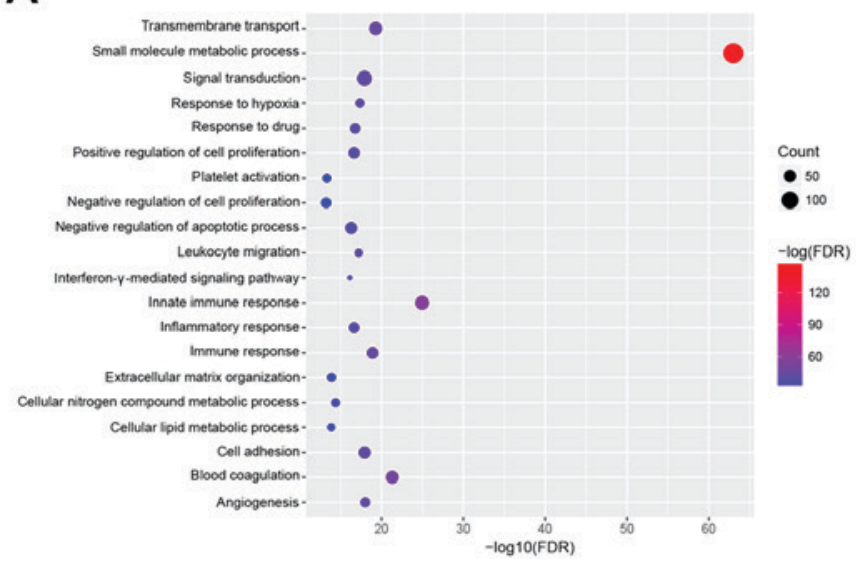

C

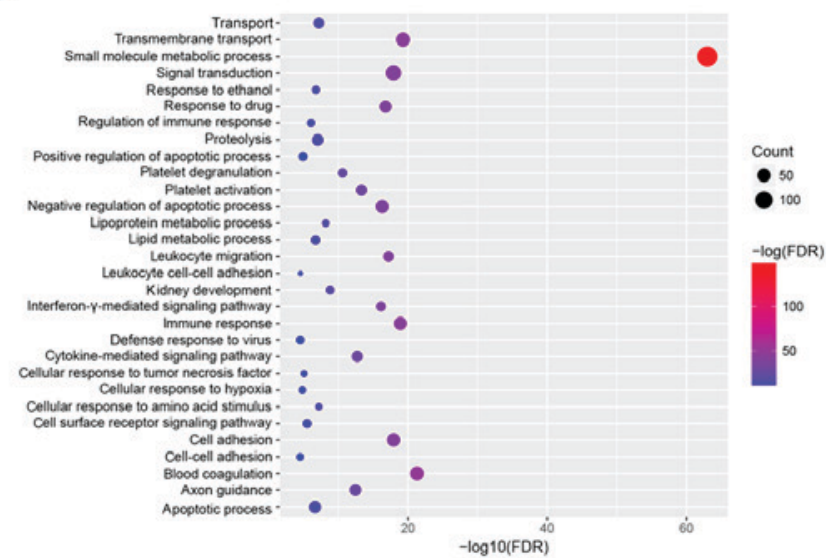

B

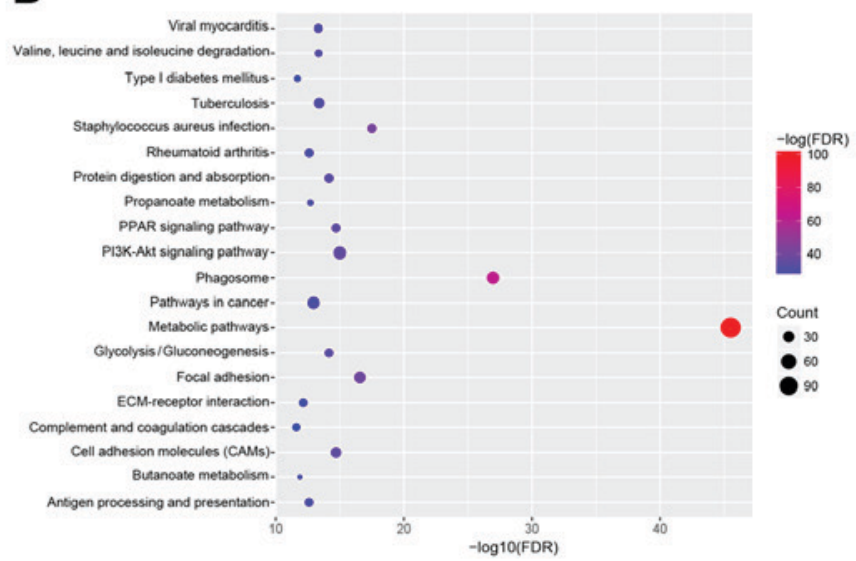

D

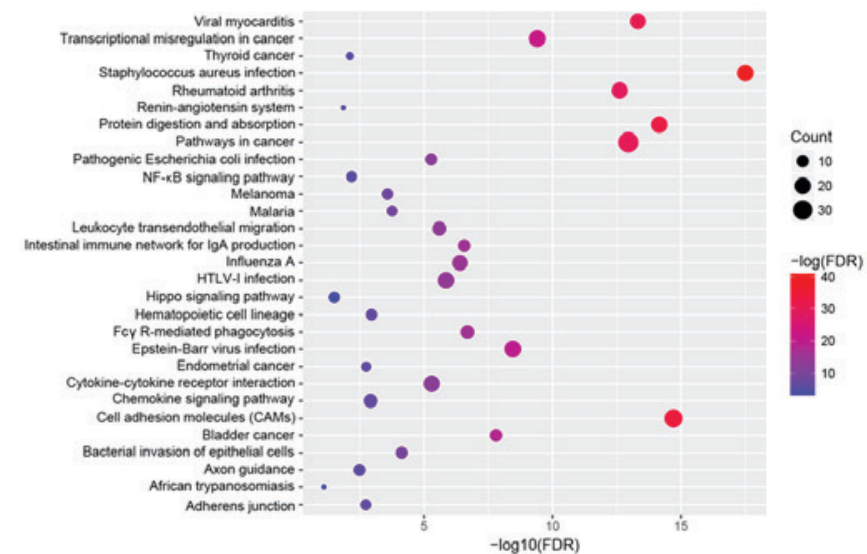

Figure 2. Bioinformatics analysis of DEGs. (A) GO analysis of top 20 terms. (B) KEGG analysis of top 20 terms. (C) GO analysis of top 30 terms, including hub genes. (D) KEGG analysis of top 30 terms, including hub gene. The count of genes enriched in terms is indicated by the node size; the ES is shown by the color, whereby blue represents low and red represents high ES. DEG, differentially expressed genes; GO, gene ontology; FDR, false discovery rate; ES, enrichment significance. 

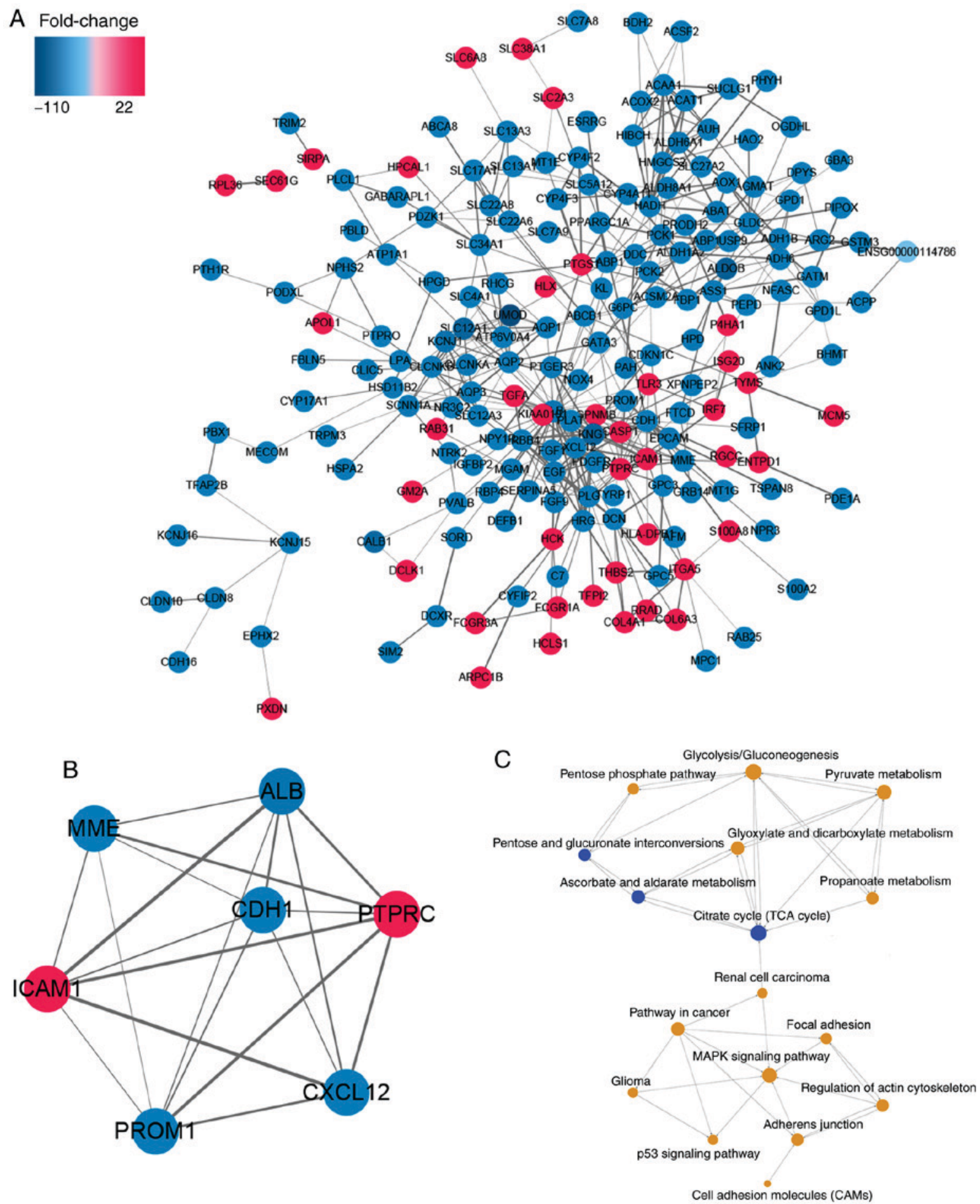

Figure 3. Hub genes detection and PPI. (A) The PPI networks of DEGs, whereby red nodes represent upregulated and blue nodes represent downregulated genes. (B) The most significant module screened from the PPI network. (C) Pathway-network analysis of DEGs based on the Gene-Cloud of Biotechnology Information online tool. DEG, differentially expressed genes; PPI, protein-protein network.

tyrosine phosphatase receptor type C (PTPRC), intercellular adhesion molecule 1 (ICAMI) in this module. The mRNA and protein expression levels of the 5 downregulated hub genes are demonstrated in Fig. 4 , and that of the 2 upregulated hub genes are shown in Fig. 5. As suggested by Figs. 4 and 5, MME, CXCL12, $C D H 1, A L B$ and $P R O M 1$ expression levels were significantly lower in ccRCC tissue compared with normal controls, whereas $I C A M 1$ and PTPRC expression levels were significantly higher (calculated by one-way ANOVA test). Survival analysis of the hub genes is presented in Fig. 6, indicating that altered $M M E$, $C D H 1$ and ICAMI were associated with the prognosis of ccRCC. However, the prognosis value of CXCL12, PROM1, $A L B$ and $P T P R C$ had no statistical significance.

\section{Discussion}

In the present study, a total of 805 DEGs including 403 upand 402 downregulated genes were selected. The present 
A a

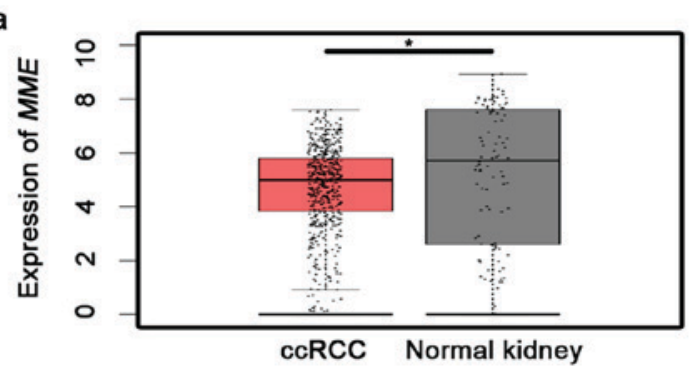

B a

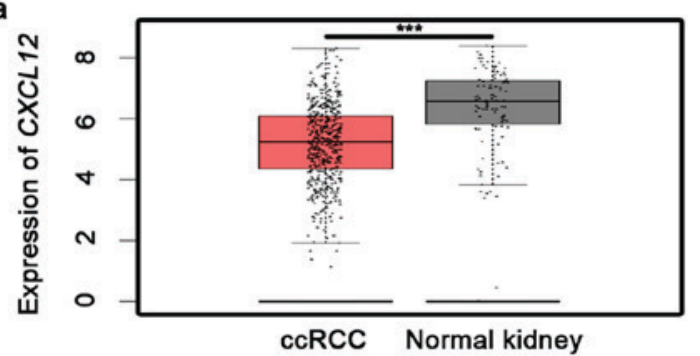

C a

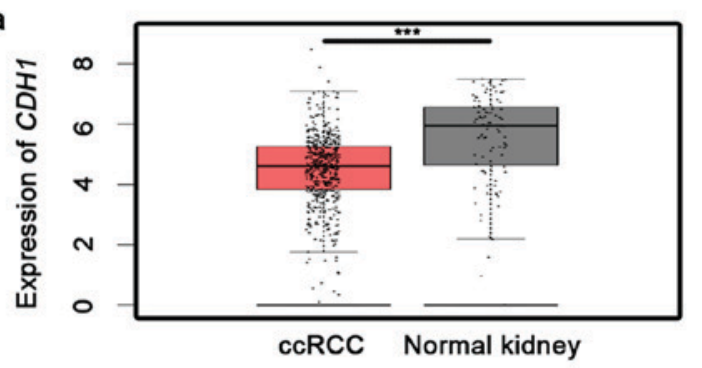

D a

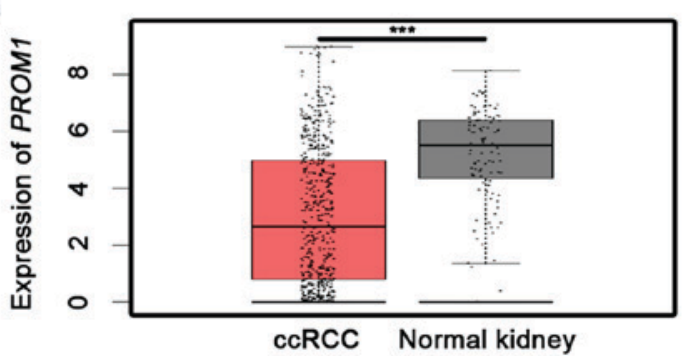

E a

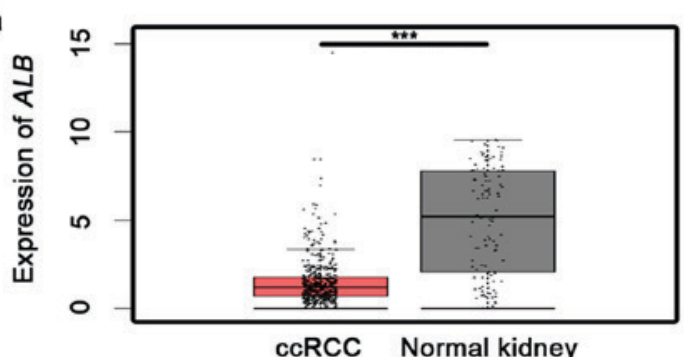

b

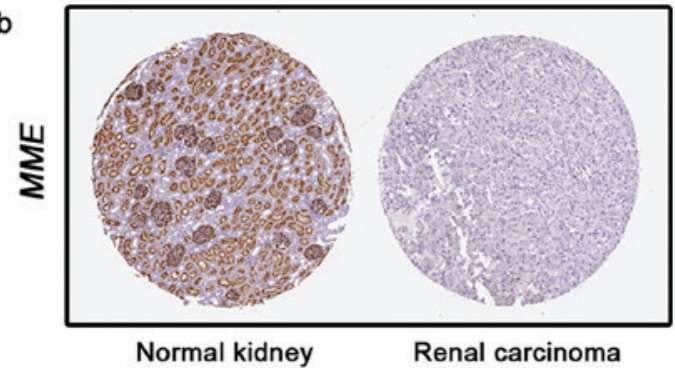

b

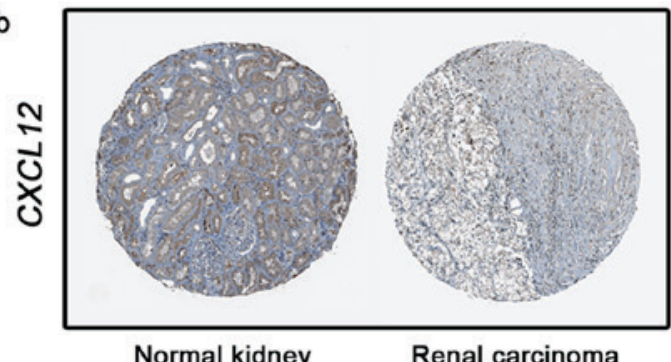

Normal kidney

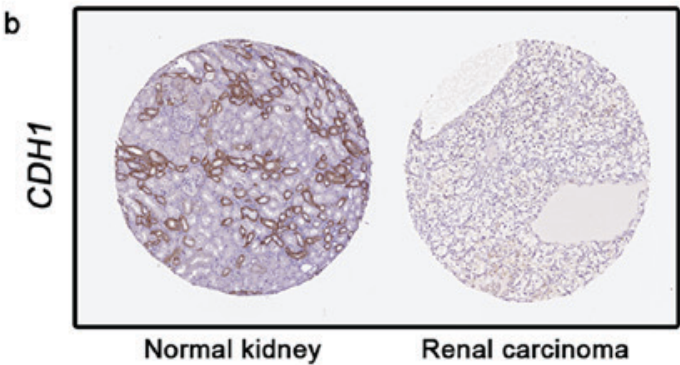

b

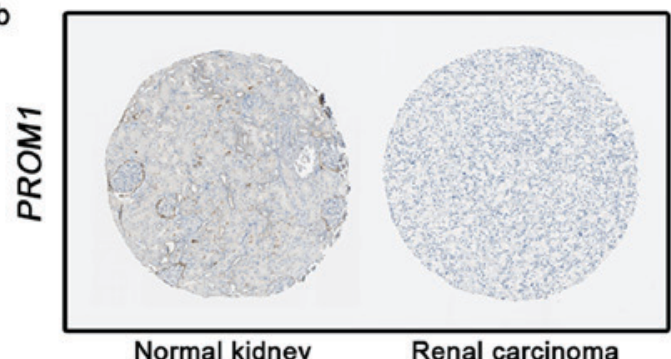

b

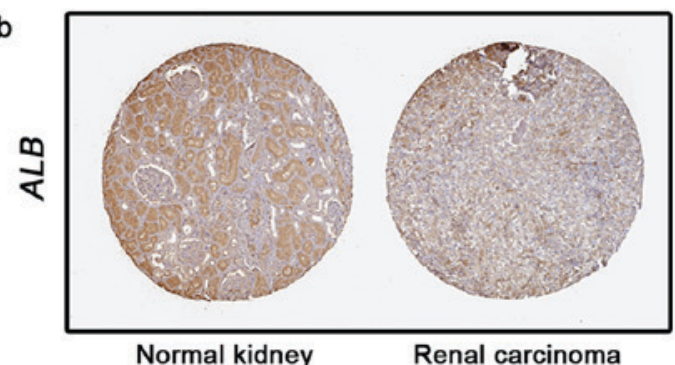

Figure 4. Analysis of downregulated hub genes. Analysis of 5 downregulated hub genes in ccRCC tissues and normal kidney tissues as follows: (A) $M M E$, (B) CXCL12, (C) CDH1, (D) PROM1 and (E) ALB. a, Transcriptional level (from GEPIA database, one-way ANOVA was used for differential analysis) and b, immunohistochemistry images obtained from translational level analyses of the Human Protein Atlas database, for which no scale bar is available. ${ }^{*} \mathrm{P}<0.05$ and ${ }^{* * *} \mathrm{P}<0.001$. ALB, albumin; ccRCC, clear cell renal cell carcinoma; CDH1, cadherin 1; CXCL12, chemokine (C-X-C motif) ligand 12 ; MME, metallo-endopeptidase; ROM1, prominin 1.

study demonstrated that the most significant functions and pathways identified were associated with biological metabolism. Previous studies have indicated that molecular metabolisms served a comprehensive role in the process of tumor generation and development $(20,21)$. It is known that HIF and the hypoxic response serve a key role in the pathways that are involved in tumorigenesis (22). In addition to hypoxia, increased reactive oxygen species (ROS) production is another 
A

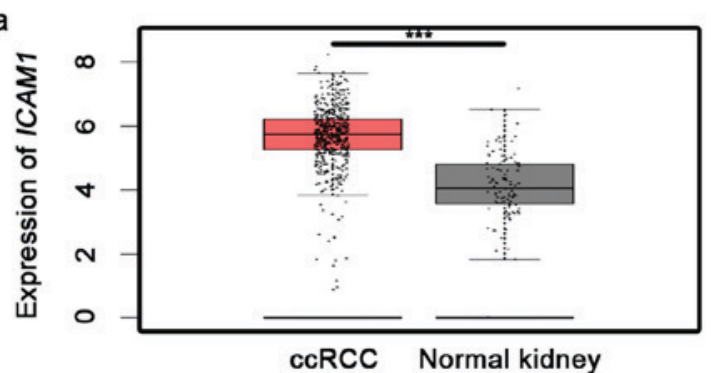

$B_{a}$

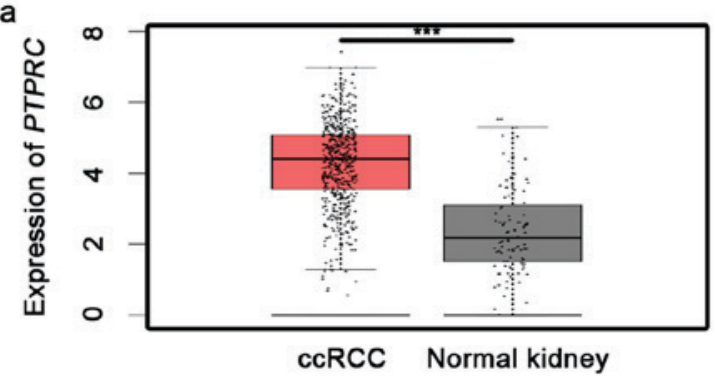

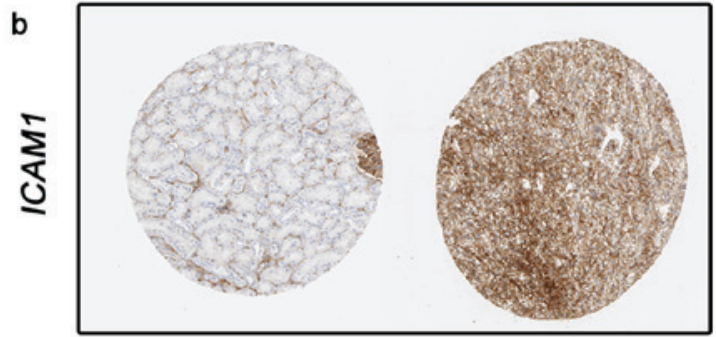

Normal kidney

Renal carcinoma

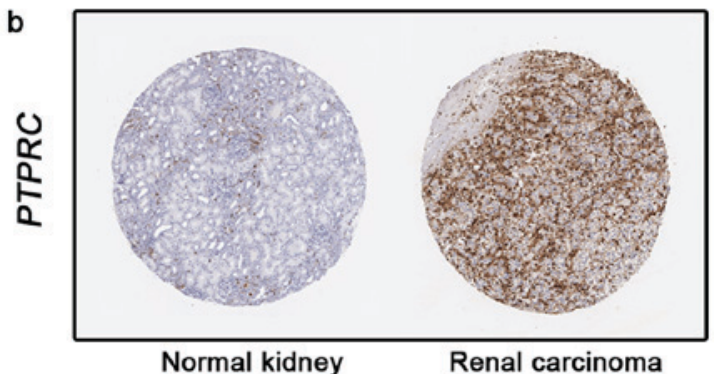

Figure 5. Analysis of upregulated hub genes. Analysis of 2 upregulated hub genes in ccRCC tissues and normal kidney tissues as follows: (A) ICAMI and (B) PTPRC. a: Transcriptional level analysis obtained from the GEPIA database; one-way ANOVA was used for differential analysis) and b: Immunohistochemistry images obtained from translational level analyses of the Human Protein Atlas database, for which no scale bar is available. ${ }^{* * *} \mathrm{P}<0.001$. ccRCC, clear cell renal cell carcinoma; PTPRC, protein tyrosine phosphatase receptor type C; ICAM1, intercellular adhesion molecule 1.

aberrant metabolic condition encountered by the majority of tumor cells (23), the balance between this oxidative stress and antioxidant systems has important effects at different stages of tumorigenesis, particularly in the initial stage (24). Metabolic disturbances, including ROS, are observed in normal physiological processes and in pathologies across a range of tissues, including in cancerous tissues; thus, it is considered that almost all core metabolic pathways are associated with cancer development (25). In addition, previous studies have reported that carbon metabolism and antioxidant response are associated with the development of ccRCC (26-28).

The present study demonstrated that the MAPK signaling pathway was associated with ccRCC. It is known that MAPK signaling pathways serve essential roles in cell proliferation and differentiation: Previous studies have demonstrated its activation in tumorigenesis and the metastasis of multiple human malignancies, including RCC (29,30). Huang et al (31) also proved this phenomenon in ccRCC, and its inhibition using anthrax lethal toxin was able to suppress ccRCC growth in vivo.

A PPI network with DEGs was constructed and listed the top degree hub genes including the following: $M M E, A L B, C X C L 12$, CDH1, PROM1, ICAM1, and PTPRC. MME, a downregulated gene in the present study, encodes a glycoprotein identified in a variety of normal and malignant tissues. This glycoprotein is particularly abundant in kidney, where it is present on the brush border of proximal tubules and on glomerular epithelium (32). Amălinei et al (33) reported that the generation of angiostatin induced by $M M E$ was responsible for the prevention of tumor growth. A previous study also demonstrated that among children with B-lineage acute lymphoblastic leukemia, $\operatorname{MME}(+)$ infants tend to have a better prognosis than those with MME(-) infants (34). The aforementioned study, combined with the survival curve and immunohistochemistry staining results in the current study, indicate that $M M E$ may be a tumor suppressor gene in ccRCC. The second hub gene was $A L B$ and it has been reported that low serum albumin level indicate a shorter progression-free survival time in patients with metastatic RCC (35). Although the present analysis indicated that $A L B$ may serve a suppressive role in the ccRCC development, this was not confirmed by the survival analysis. CXCL12, the third hub gene, encodes a stromal cell-derived $\alpha$ chemokine that serve a role in tumor growth and metastasis (36). CXCL12 was identified as a downregulated gene in the present analysis. Furthermore, Ping et al (37) reported that decreased CXCL12 in the tumor microenvironment may facilitate lymphoid malignant cells metastasis by limiting the interactions between malignant cells and surrounding cells in lymphocytic leukemia. $C D H 1$, as a member of the cadherin superfamily, may serve a critical role in apoptotic process and cell-cell adhesion (38). A previous study demonstrated that $\mathrm{CDH} 1$ expression was lower in gastric cancer and this decrease contributed to intestinal-type gastric carcinogenesis (39). Another study reported that attenuated expression of $\mathrm{CDH} 1$ had a key role in tumor invasion and metastasis (40). PROM1 was another downregulated gene in the present study, which encodes a pentaspan transmembrane glycoprotein. D'Alterio et al (41) reported PROMI expression was low in ccRCC. PROM1 has been observed to contribute to cell differentiation in numerous tissue types, including glomerular visceral (42) and tubule epithelial (43). However, the biological function of PROMI remains unclear. In RCC, PROM1 progenitor cells were able to differentiate into endothelial cells enhancing vascularization and tumor growth, which consequently promoted the development of RCC $(44,45)$.

$I C A M 1$ was the most significantly upregulated hub genes in the present analysis and is a cell adhesion molecule of the immunoglobulin superfamily. ICAM-1 expression has been reported to be upregulated in several cancer types, including 

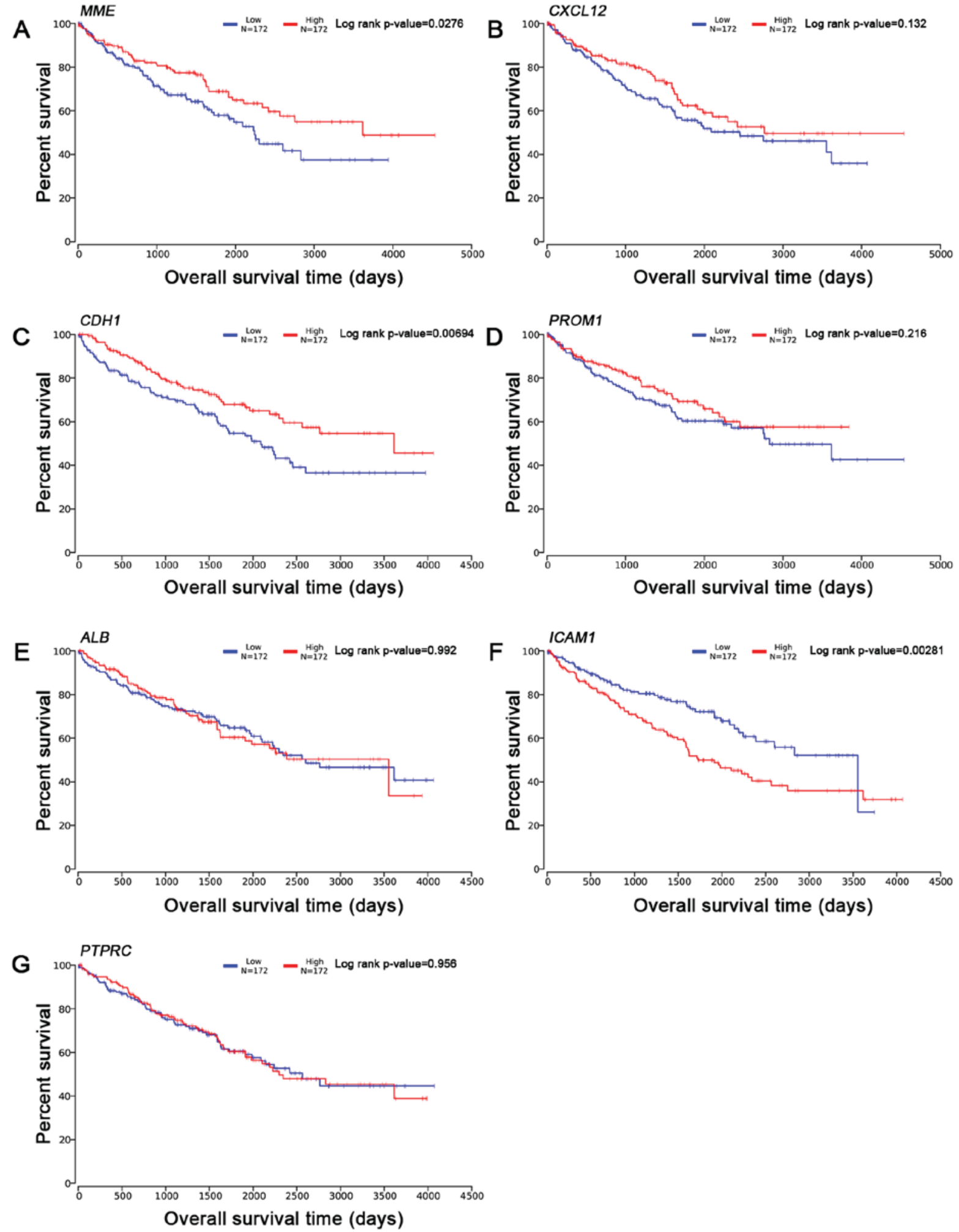

Figure 6. Overall survival time analysis (from OncoLnc database). Overall survival time analysis of 7 hub genes as follows: (A) $M M E$, (B) $C X C L 12,(\mathrm{C}) C D H 1$, (D) PROM1, (E) ALB, (F) ICAM1 and (G) PTPRC. ALB, albumin; CDH1, cadherin 1; CXCL12, chemokine (C-X-C motif) ligand 12; MME, metallo-endopeptidase; ROM1, prominin 1; PTPRC, protein tyrosine phosphatase receptor type C; ICAM1, intercellular adhesion molecule 1.

thyroid carcinoma, hepatocellular carcinoma, oral cancer, RCC and bladder cancer (46-50). In ccRCC, ICAM1 expression was upregulated following treatment with a series of cytokines, including tumor necrosis factor $\alpha$, interferon- $\gamma$ and phorbol myristate acetate (51). Furthermore, as an independent predictor for the prognosis of ccRCC, its high expression in tumor cells indicates a shorter survival time (52). The results of studies are in accordance with the present analysis. PTPRC was another upregulated hub gene, encoding a member of the PTP family (53). PTPs are known to be signaling molecules that regulate a variety of cellular processes, including cell growth, differentiation, mitosis and oncogenic 
transformation (54). Clark et al (55) reported that galectin-3 served an anti-apoptotic role in diffuse large B-cell lymphoma via binding to PTPRC product.

Although our study shows that the seven Hub genes were associated with the occurrence or development of ccRCC, the survival analysis by OncoLnc database showed that altered $M M E, C D H I$ and ICAMI were associated with the prognosis of ccRCC, but CXCL12, PROM1, ALB and PTPRC were not. On one hand, the prognosis might not be affected by the differentially expressed hub genes (CXCL12, PROM1, ALB and $P T P R C$ ). On the other hand, they might involve in the carcinogenesis of ccRCC through the interconnection with other genes, and might not be sufficient as an independent risk factor in the progression of ccRCC.

In conclusion, the present study used various bioinformatics analysis tools to identify 7 novel hub genes (MME, ALB, CXCL12, $C D H 1, P R O M 1, I C A M 1$ and PTPRC), which may serve key roles in the tumorigenesis of human ccRCC. These genes may serve as novel biomarkers of ccRCC. However, the lack of in vivo and in vitro experiments is a limitation of the present study, further experiments are required to confirm the present findings, and confirm the role of these candidate genes in ccRCC.

\section{Acknowledgements}

The authors would like to thank Ms. Shanshan Zhang and Ms. Danni Shan (Zhongnan Hospital of Wuhan University, Wuhan, China) for their technical assistance.

\section{Funding}

The present study was supported in part by the Zhongnan Hospital of Wuhan University Science, Technology and Innovation Seed Fund (grant no. cxpy20160010) and Natural Sciences Foundation of Hubei Province (grant no. 2014CFA006). The funders had no role in the design of the study, the collection, analysis, and interpretation of data, or in writing the manuscript.

\section{Availability of data and materials}

All data generated or analyzed during this study are included in this published article.

\section{Authors' contributions}

JW, LY, YX and XW conceived and designed the study. JW, LY, XL, GW and YX collected the data and performed the analysis. JW, LY, YZ, KQ. and YX analyzed the results. JW, YX and XW contributed analysis tools. JW, LY, YX and XW contributed to the writing of the manuscript. All authors reviewed the manuscript.

\section{Ethics approval and consent to participate}

Not applicable.

\section{Consent for publication}

Not applicable.

\section{Competing interests}

The authors declare that they have no competing interests.

\section{References}

1. Sanfilippo KM, McTigue KM, Fidler CJ, Neaton JD, Chang Y, Fried LF, Liu S and Kuller LH: Hypertension and obesity and the risk of kidney cancer in 2 large cohorts of US men and women. Hypertension 63: 934-941, 2014.

2. Frew IJ and Moch H: A clearer view of the molecular complexity of clear cell renal cell carcinoma. Annu Rev Pathol 10: 263-289, 2015.

3. Papale M, Vocino G, Lucarelli G, Rutigliano M, Gigante M, Rocchetti MT, Pesce F, Sanguedolce F, Bufo P, Battaglia M, et al: Urinary RKIP/p-RKIP is a potential diagnostic and prognostic marker of clear cell renal cell carcinoma. Oncotarget 8: 40412-40424, 2017.

4. Neely BA, Wilkins CE, Marlow LA, Malyarenko D, Kim Y, Ignatchenko A, Sasinowska H, Sasinowski M, Nyalwidhe JO, Kislinger T, et al: Proteotranscriptomic analysis reveals stage specific changes in the molecular landscape of Clear-cell renal cell carcinoma. PLoS One 11: e0154074, 2016.

5. Gowrishankar B, Ibragimova I, Zhou Y, Slifker MJ, Devarajan K, Al-Saleem T, Uzzo RG and Cairns P: MicroRNA expression signatures of stage, grade, and progression in clear cell RCC. Cancer Biol Ther 15: 329-341, 2014.

6. Gossage L, Eisen T and Maher ER: VHL, the story of a tumour suppressor gene. Nat Rev Cancer 15: 55-64, 2015.

7. Escudier B, Szczylik C, Porta C and Gore M: Treatment selection in metastatic renal cell carcinoma: Expert consensus. Nat Rev Clin Oncol 9: 327-337, 2012.

8. Mandriota SJ, Turner KJ, Davies DR, Murray PG, Morgan NV, Sowter HM, Wykoff CC, Maher ER, Harris AL, Ratcliffe PJ, et al: HIF activation identifies early lesions in VHL kidneys: Evidence for site-specific tumor suppressor function in the nephron. Cancer Cell 1: 459-468, 2002.

9. Kulasingam V and Diamandis EP: Strategies for discovering novel cancer biomarkers through utilization of emerging technologies. Nat Clin Pract Oncol 5: 588-599, 2008.

10. Yang M, Chen BL, Huang JB, Meng YN, Duan XJ, Chen L, Li LR and Chen YP: Angiogenesis-related genes may be a more important factor than matrix metalloproteinases in bronchopulmonary dysplasia development. Oncotarget 8: 18670-18679, 2017.

11. Xiao J, Liu A, Lu X, Chen X, Li W, He S, He B and Chen Q: Prognostic significance of TCF21 mRNA expression in patients with lung adenocarcinoma. Sci Rep 7: 2027, 2017.

12. Peterson LE: CLUSFAVOR 5.0: Hierarchical cluster and principal-component analysis of microarray-based transcriptional profiles. Genome Biol 3: SOFTWARE0002, 2002.

13. Ito K and Murphy D: Application of ggplot2 to pharmacometric graphics. CPT Pharmacometrics Syst Pharmacol 2: e79, 2013.

14. Szklarczyk D, Franceschini A, Kuhn M, Simonovic M, Roth A, Minguez P, Doerks T, Stark M, Muller J, Bork P, et al: The STRING database in 2011: Functional interaction networks of proteins, globally integrated and scored. Nucleic Acids Res 39 (Database Issue): D561-D568, 2011.

15. Shannon P, Markiel A, Ozier O, Baliga NS, Wang JT, Ramage D, Amin N, Schwikowski B and Ideker T: Cytoscape: A software environment for integrated models of biomolecular interaction networks. Genome Res 13: 2498-2504, 2003.

16. Mutwil M, Usadel B, Schütte M, Loraine A, Ebenhöh O and Persson S: Assembly of an interactive correlation network for the Arabidopsis genome using a novel heuristic clustering algorithm. Plant Physiol 152: 29-43, 2010.

17. Tang Z, Li C, Kang B, Gao G, Li C and Zhang Z: GEPIA: A web server for cancer and normal gene expression profiling and interactive analyses. Nucleic Acids Res 45: W98-W102, 2017.

18. Interactive human protein atlas launches. Cancer Discov 5: 339, 2015.

19. Anaya J: OncoLnc: Linking TCGA survival data to mRNAs, miRNAs, and lncRNAs. Peer J Computer Sci 2: e67, 2016.

20. Tian Y, Du W, Cao S, Wu Y, Dong N, Wang Y and Xu Y: Systematic analyses of glutamine and glutamate metabolisms across different cancer types. Chin J Cancer 36: 88, 2017.

21. Meng X, Zhong J, Liu S, Murray M and Gonzalez-Angulo AM: A new hypothesis for the cancer mechanism. Cancer Metastasis Rev 31: 247-268, 2012. 
22. Mimeault M and Batra SK: Hypoxia-inducing factors as master regulators of stemness properties and altered metabolism of cancer- and metastasis-initiating cells. J Cell Mol Med 17: 30-54, 2013.

23. Gorrini C,Harris IS and Mak TW: Modulation of oxidative stress as an anticancer strategy. Nat Rev Drug Discov 12: 931-947, 2013.

24. Harris IS, Treloar AE, Inoue S, Sasaki M, Gorrini C, Lee KC, Yung KY, Brenner D, Knobbe-Thomsen CB, Cox MA, et al: Glutathione and thioredoxin antioxidant pathways synergize to drive cancer initiation and progression. Cancer Cell 27: 211-222, 2015.

25. Cairns RA and Mak TW: Fire and water: Tumor cell adaptation to metabolic conditions. Exp Cell Res 356: 204-208, 2017.

26. Hakimi AA, Reznik E, Lee CH, Creighton CJ, Brannon AR, Luna A, Aksoy BA, Liu EM, Shen R, Lee W, et al: An integrated metabolic atlas of clear cell renal cell carcinoma. Cancer Cell 29: 104-116, 2016

27. Li B, Qiu B, Lee DS, Walton ZE, Ochocki JD, Mathew LK, Mancuso A, Gade TP, Keith B, Nissim I, et al: Fructose-1,6-bisphosphatase opposes renal carcinoma progression. Nature 513: 251-255, 2014.

28. Sudarshan S, Karam JA, Brugarolas J, Thompson RH, Uzzo R Rini B, Margulis V, Patard JJ, Escudier B and Linehan WM: Metabolism of kidney cancer: From the lab to clinical practice. Eur Urol 63: 244-251, 2013.

29. Chang L and Karin M: Mammalian MAP kinase signalling cascades. Nature 410: 37-40, 2001.

30. Johnson GL and Lapadat R: Mitogen-activated protein kinase pathways mediated by ERK, JNK, and p38 protein kinases. Science 298: 1911-1912, 2002.

31. Huang D, Ding Y, Luo WM, Bender S, Qian CN, Kort E, Zhang ZF, VandenBeldt K, Duesbery NS, Resau JH, et al: Inhibition of MAPK kinase signaling pathways suppressed renal cell carcinoma growth and angiogenesis in vivo. Cancer Res 68 : 81-88, 2008.

32. Noordmans GA, Caputo CR, Huang Y, Sheehan SM, Bulthuis M, Heeringa P, Hillebrands JL, van Goor H and Korstanje R: Genetic analysis of mesangial matrix expansion in aging mice and identification of Far2 as a candidate gene. J Am Soc Nephrol 24: 1995-2001, 2013

33. Amălinei C, Căruntu ID, Giuscă SE and Bălan RA: Matrix metalloproteinases involvement in pathologic conditions. Rom J Morphol Embryol 51: 215-228, 2010.

34. Maguer-Satta V, Besancon R and Bachelard-Cascales E: Concise review: Neutral endopeptidase (CD10): A multifaceted environment actor in stem cells, physiological mechanisms, and cancer Stem Cells 29: 389-396, 2011.

35. Stenman M, Laurell A and Lindskog M: Prognostic significance of serum albumin in patients with metastatic renal cell carcinoma. Med Oncol 31: 841, 2014.

36. Ray P, Lewin SA, Mihalko LA, Lesher-Perez SC, Takayama S, Luker KE and Luker GD: Secreted CXCL12 (SDF-1) forms dimers under physiological conditions. Biochem J 442: 433-442, 2012

37. Ping L, Ding N, Shi Y, Feng L, Li J, Liu Y, Lin Y, Shi C, Wang X, Pan Z, et al: The Bruton's tyrosine kinase inhibitor ibrutinib exerts immunomodulatory effects through regulation of tumor-infiltrating macrophages. Oncotarget 8: 39218-39229, 2017.

38. Chen I, Mathews-Greiner L, Li D, Abisoye-Ogunniyan A, Ray S, Bian Y, Shukla V, Zhang X, Guha R, Thomas C, et al: Transcriptomic profiling and quantitative high-throughput (qHTS) drug screening of CDH1 deficient hereditary diffuse gastric cancer (HDGC) cells identify treatment leads for familial gastric cancer. J Transl Med 15: 92, 2017.

39. Khouzam RA, Molinari C, Salvi S, Marabelli M, Molinaro V, Orioli D, Saragoni L, Morgagni P, Calistri D and Ranzani GN: Digital PCR identifies changes in CDH1 (E-cadherin) transcription pattern in intestinal-type gastric cancer. Oncotarget 8 : 18811-18820, 2017

40. van Roy F and Berx G: The cell-cell adhesion molecule E-cadherin. Cell Mol Life Sci 65: 3756-3788, 2008.
41. D'Alterio C, Cindolo L, Portella L, Polimeno M, Consales C, Riccio A, Cioffi M, Franco R, Chiodini P, Carteni G, et al: Differential role of CD133 and CXCR4 in renal cell carcinoma. Cell Cycle 9: 4492-4500, 2010

42. Ronconi E, Sagrinati C, Angelotti ML, Lazzeri E, Mazzinghi B, Ballerini L, Parente E, Becherucci F, Gacci M, Carini M, et al: Regeneration of glomerular podocytes by human renal progenitors. J Am Soc Nephrol 20: 322-332, 2009.

43. Sagrinati C, Netti GS, Mazzinghi B, Lazzeri E, Liotta F, Frosali F, Ronconi E, Meini C, Gacci M, Squecco R, et al: Isolation and characterization of multipotent progenitor cells from the Bowman's capsule of adult human kidneys. J Am Soc Nephrol 17: 2443-2456, 2006.

44. Bruno S, Bussolati B, Grange C, Collino F, Graziano ME, Ferrando U and Gamussi G: CD133+ renal progenitor cells contribute to tumor angiogenesis. Am J Pathol 169: 2223-2235, 2006.

45. Bussolati B, Bruno S, Grange C, Buttiglieri S, Deregibus MC, Cantino D and Camussi G: Isolation of renal progenitor cells from adult human kidney. Am J Pathol 166: 545-555, 2005.

46. Roland CL, Harken AH, Sarr MG and Barnett CC Jr: ICAM-1 expression determines malignant potential of cancer. Surgery 141: 705-707, 2007.

47. Usami Y, Ishida K, Sato S, Kishino M, Kiryu M, Ogawa Y, Okura M, Fukuda Y and Toyosawa S: Intercellular adhesion molecule-1 (ICAM-1) expression correlates with oral cancer progression and induces macrophage/cancer cell adhesion. Int J Cancer 133: 568-578, 2013

48. Buitrago D, Keutgen XM, Crowley M, Filicori F, Aldailami H, Hoda R, Liu YF, Hoda RS, Scognamiglio T, Jin M, et al: Intercellular adhesion molecule-1 (ICAM-1) is upregulated in aggressive papillary thyroid carcinoma. Ann Surg Oncol 19: 973-980, 2012

49. Tanabe K, Campbell SC, Alexander JP, Steinbach F, Edinger MG, Tubbs RR, Novick AC and Klein EA: Molecular regulation of intercellular adhesion molecule 1 (ICAM-1) expression in renal cell carcinoma. Urol Res 25: 231-238, 1997.

50. Tanabe K, Alexander JP, Steinbach F, Campbell S, Novick AC and Klein EA: Retroviral transduction of intercellular adhesion molecule-1 enhances endothelial attachment of bladder cancer. Urol Res 25: 401-405, 1997.

51. Tomita Y, Nishiyama T, Watanabe H, Fujiwara M and Sato S: Expression of intercellular adhesion molecule-1 (ICAM-1) on renal-cell cancer: Possible significance in host immune responses. Int J Cancer 46: 1001-1006, 1990.

52. Shi X, Jiang J, Ye X, Liu Y, Wu Q and Wang L: Prognostic prediction and diagnostic role of intercellular adhesion molecule-1 (ICAM1) expression in clear cell renal cell carcinoma. J Mol Histol 45: 427-434, 2014.

53. Williamson AJ, Pierce A, Jaworska E, Zhou C, Aspinall-O'Dea M, Lancashire L, Unwin RD, Abraham SA, Walker MJ, Cadecco S, et al: A specific PTPRC/CD45 phosphorylation event governed by stem cell chemokine CXCL12 regulates primitive hematopoietic cell motility. Mol Cell Proteomics 12: 3319-3329, 2013.

54. Stanford SM, Ahmed V, Barrios AM and Bottini N: Cellular biochemistry methods for investigating protein tyrosine phosphatases. Antioxid Redox Signal 20: 2160-2178, 2014.

55. Clark MC, Pang M, Hsu DK, Liu FT, de Vos S, Gascoyne RD, Said J and Baum LG: Galectin-3 binds to CD45 on diffuse large B-cell lymphoma cells to regulate susceptibility to cell death. Blood 120: 4635-4644, 2012.

This work is licensed under a Creative Commons Attribution-NonCommercial-NoDerivatives 4.0 International (CC BY-NC-ND 4.0) License. 